Original Research Paper

\title{
Cognitive Development of College Students and their Achievement in Geometry: An Evaluation using Piaget's Theory and Van Hiele's Levels of Thinking
}

\author{
Ronald Sumaya Decano \\ Institute of Education Davao del Norte State College, New Visayas, Panabo City, Philippines
}

\author{
Article history \\ Received: 08-07-2017 \\ Revised: 31-08-2017 \\ Accepted: 14-09-2017 \\ E-mail: ronaldsdecano@gmail.com
}

\section{Introduction}

The Philippine education system is currently enhancing its basic education curriculum through an enhanced $\mathrm{K}$ to 12 programs. This program is consistent with Article XIV, Section 2(1) of the 1987 Philippine Constitution which ensures the state's commitment to establish, maintain and support a complete, adequate and integrated system of education relevant to the needs of the people and society.

One of the reasons why the government implements the program is because they found that the

\begin{abstract}
The study evaluated the cognitive development levels of college students and their achievement in Geometry using Piaget's Test of Logical Operations and Van Hiele's Levels of Thinking. The researcher employed quantitative approach to research. There were 105 respondents in which 71 of them fit the Van Hiele modified case/criterion (M3) 3 of 5 correct answers. Findings revealed that most of the college students were identified as concrete operational thinkers using Piaget's theory of concrete and formal operations who possessed the levels of classification, seriation and transitivity. Using Van Hiele's levels of thinking, most of them were classified as holistic thinkers. Students whose ages ranging from 20 years old and up were performing better in Geometry as compared to the other age brackets. It also revealed that male students were performing better than female students. In the cognitive development levels using Piaget's theory on concrete and formal operations, there is a significant difference when grouped according to age and year levels but found a non-significant difference when grouped according to sex. Significant positive relationships revealed among Van Hiele's levels of thinking, Piaget's theory of concrete and formal operations and Geometry achievement test. Van Hiele's levels of deductive and rigorous thinking and Piaget's levels of transitivity, proportionality and correlation are significant predictors in the achievement of students in Geometry. This implies further that to be successful in learning Geometry and mathematics in general, a college student must reach Van Hiele' level 3 - deductive thinking and Piaget's level 3 - transitivity.
\end{abstract}

Keyword: Cognitive Development, Piaget's Test of Logical Operation, Van Hiele's Level of Thinking, Geometry Achievement professionals cannot compete academically with the rest of the Foreign workers abroad because of the short duration of 10-year basic education program received which is different to the other countries that most have 12-year basic education curriculum.

The subject matter as prescribed by mathematics educators has been a major factor in determining the sequencing of secondary school mathematics curriculum. These subjects are sequenced to suit the needs of the students according to year levels. In secondary mathematics curriculum before the 
implementation of the $\mathrm{K}$ to 12 program, the subjects Algebra, Geometry, Trigonometry and Statistics were offered during the First, Second, Third and Fourth year levels, respectively.

However, in spite of offering the said subjects and the efforts to lift the country's standing in international surveys in mathematics and sciences, still the Trend in International Mathematics and Science Study (TIMSS) revealed that the country was ranked close to the bottom. The decline of students' interest and performance in Mathematics is evident in most universities and colleges in the Philippines particularly in Davao City. This could be the reason why most Mathematics-related programs do not have any strict implementation of admission and retention policies because of the scarcity of possible enrollees. Aside from the alarming decline of enrolment, another problem encountered by most Mathematics teachers is the swelling of students' drop-outrates.

This study considered the two theories which postulate that students cannot learn materials if they have not reached a particular level of cognitive development. These theories are Piaget's Theory of Cognitive Development and Van Hiele's Levels of Thinking. To some extent, the said theories are complementary because they focus on different aspects of cognitive development and thinking and discuss the learning process of the students. These theories are important since they speak to what the teachers can teach students and to where they want students to be when they graduate (Wankat and Oreovics, 1983).

\section{Objectives of the Problem}

The study was conducted to evaluate the cognitive development levels and thinking of the Mathematics major students and their achievement in Geometry. They were evaluated using Piaget's Theory of Concrete and Formal Operations and Van Hiele's Levels of Thinking. Specifically, it aimed to:

- Describe the demographic profile of college students in terms of age, gender and year level

- Determine the level of cognitive development of college students in Geometry based on Piaget's theory of concrete and Formal operations and van Hiele's levels of thinking

- Ascertain the level of achievements of college students in Geometry

- Compare the cognitive development levels when grouped according to age, gender and year level

- Correlate among levels of cognitive development and the achievement of the college students in Geometry

- Identify the cognitive levels of development that best predict college students' achievement in Geometry

\section{Hypotheses of the Study}

The following were the null hypotheses tested in this study:

$\mathrm{H}_{01}$ : There is no significant difference in the cognitive development levels and thinking when grouped according to age, gender and year level

$\mathrm{H}_{02}$ : There is no significant relationship among levels of cognitive development theories and the achievement of college students in Geometry

$\mathrm{H}_{03}$ : There is no cognitive development levels best predicts students' achievement in Geometry

\section{Review of Related Studies}

This section presents the review of literatures and related studies taken from different sources like books, publications, encyclopedia, periodicals, journals, internet, magazines and even those unpublished documents that are relevant to the research objectives of this study.

\section{Cognitive Development}

Cognitive development is the construction of thought processes which is nurtured from childhood to adulthood (Wells, 2004). Before the infants learned language, it was believed that they lacked the ability to understand complex ideas. When they learned language, the child becomes aware of his/her surroundings. He/she becomes interested in gathering, sorting and processing information using tangible objects to develop perception and thinking skills.

Cognitive development refers to how person perceives, thinks and gains understanding of his/her world through the interaction of genetic and learned factors. This contains the very best empirical and theoretical work on the development of perception, memory, language, concepts, thinking, problem solving, metacognitionand social cognition (Kuhn, 2012).

\section{Piaget's Theory on Cognitive Development}

Jean Piaget was a Swiss psychologist who proposed a comprehensive theory about the nature and development of human intelligence. Piaget claimed that cognitive development is at the center of human organism and language is contingent on cognitive development. He believed that reality is a dynamic system of continuous change and as such is defined in reference to the two conditions that define dynamic systems that change.

The Sensorimotor Stage (Birth to 2 years old) is the first stage Piaget uses to define cognitive development. During this period, infants are busy discovering relationships between their bodies and the environment. Researchers have discovered that infants have relatively well developed sensory abilities. The child 
relies on seeing, touching, sucking, feeling and using their senses to learn things about themselves and the environment. Piaget calls this the sensorimotor stage because the early manifestations of intelligence appear from sensory perceptions and motor activities.

In the Preoperational stage (ages 2 to 4 ) a child will react to all similar objects as though they are identical. This means the child will make inferences from one specific to another. In this stage, the child is not yet able to conceptualize abstractly and needs concrete physical situations. Objects are classified in simple ways, especially by important features.

During this Concrete operations (ages 7 to 11), children begin to reason logically and organize thoughts coherently. The have the ability to master most types of conservation experiments and begins to understand reversibility. They are capable of concrete problem-solving. However, they can only think about actual physical objects and cannot handle abstract reasoning. They have difficulty understanding abstract or hypothetical concepts. This stage is also characterized by a loss of egocentric thinking. As suggested by Lawson and Renner (1974), a concrete operational student does not become formal operational by constantly being confronted with formal operational tasks or concrete.

In Formal operations (beginning at ages 11 to 15 ), the child does not require concrete objects to make rational judgments. He or she is capable of deductive and hypothetical reasoning. The Formal Operational stage is the final stage in Piaget's theory. It begins at approximately 11 to 12 years of age and continues throughout adulthood. They are characterized by the ability to formulate hypotheses and systematically test them to arrive at an answer to a problem. Research conducted by Higgins-Trenk and Oaite (1971; Renner and Stafford, 1972) revealed that majority of the adolescents and young adults showed formal operational thinking.

The individual in the formal stage is also able to think abstractly and to understand the form or structure of a mathematical problem. Another characteristic of the individual is their ability to reason contrary to fact. That is, if they are given a statement and asked to use it as the basis of an argument they are capable of accomplishing the task.

\section{Van Hiele's Levels of Thinking}

Dina and Pierre van Hiele suggested that children may learn geometry along the lines of a structure for reasoning. The model asserts that the learner moves sequentially through five levels of understanding.

The Van Hiele's model asserts that the learner moves sequentially through five levels of understanding.
Different numbering systems are found in the literature but the Van Hieles spoke of levels 0 through 4 where Level 0 (holistics thinking), Level 1 (analytic thinking), Level 2 (abstract thinking), Level 3 (deductive thinking) and Level 4 (rigorous thinking).

\section{Level 0: Holistics Thinking}

The students at this level recognize about basic geometric concepts by means of visual presentation of the concept as a whole without regard to properties of its components. For example, students recognize triangles, squares, parallelograms and so forth by their shape, but they do not explicitly identify the properties of these figures (de Villiers, 1996).

\section{Level 1: Analytic Thinking}

Students analyze figures in terms of their components and relationships among components and perceive properties or rules of a class of properties of shapes empirically, but properties or rules are perceived as isolated and unrelated. Students begin to identify properties of shapes and learn to use appropriate vocabulary related to properties, but do not make connections between different shapes and their properties (Teppo, 1991).

\section{Level 2: Abstract Thinking}

At this level, students logically relate previously discovered properties or rules by givingor following informal arguments such as object representation through drawings, illustrations, etc. (Feza and Webb, 2005). They can translate their ideas into concept to easily understand their surroundings.

\section{Level 3: Deductive Thinking}

Students at this level possess high level of intellectual maturity where they can make their own proof to understand something. Hoffer (1981) explains that the student understands the significance of deduction and the role of postulates, axioms, theorems and proof. Mayberry (1983) further points out that the meaning of necessary and sufficient conditions in a definition are understood.

\section{Level 4: Rigorous Thinking}

Students at this level can work in different geometric or axiomatic systems and would most likely beenrolled in a tertiary education in geometry (Teppo, 1991; Pegg, 1995). According to Atebe and Schäfer (2010), the students at this level are able to establish that the locus of all points equidistant from a fixed point is a circle in Euclideangeometry, whereas, the same locus is a square in Taxicab geometry. 


\section{Methodology}

Presented in this section are the discussions on research design, locale of the study, the subject respondents, sampling procedures, research instruments, data-gathering procedures and statistical techniques.

\section{Research Design}

Quantitative approach was used to determine the extent of relationship between the two theories and students' achievement in Geometry. Mateya (2008) explained that quantitative research is used to answer questions about relationships among measured variables with the purpose of explaining, predicting and controlling phenomena.

\section{Respondents of the Study}

There were 105 respondents who participated in the study. They were the college students enrolledat Holy Cross of Davao College, Davao City, Philippines. The students who comprised the first year and fourth year were taking-up Bachelor of Science in Education and Bachelor of Arts major in Mathematics. The study focused only to students who major mathematics so that relevant curriculum may be designed or revised to suit the cognitive levels of the students. Since there were only few enrolled in these two courses, the researcher considered all students from first year to fourth year.

\section{Research Instruments}

The researcher used three (3) types of questionnaires namely; Van Hiele's Geometry Test (VHGT), Piaget's Test of Logical Operations (PTLO) and Researchermade Geometry Achievement Test (GAT) as means of gathering data for the study. These questionnaires were taken based from the different literature reviewed and validated by mathematics teachers. The said questionnaires were pilot tested for the reliability tests.

Table 1 shows the identification of case/criterion the college students belong. The process of analysis that is used to identify students' Van Hiele's levels of thinking was taken from the criteria suggested by Usiskin (1992) which consisted of first assigning a students a weighted sum score based on correctly answering the allotted number of questions in each block as shown in Table 2. As an example, if a student answers at least 3 questions correctly for the first and second blocks but not for the remaining blocks of questions, then the student would be given a weighted score of $3(1+2+0+0+0)$ and that student's understanding belongs to level 2. Moreover, if the student answers at least 3 of 5 questions of the first three blocks of questions, the student would be given a weighted score of $7(1+2+4+0+0)$ and that the student's understanding would be classified as level 3 . The highest score obtained by the students was $1+2+4+8+16=31$ points. This analysis would be utilized if the students does not fit the classical cases.

Van Hiele Geometry Test is a 25 -item multiple choice test designed by Van Hiele (1986) himself to determine the level of understanding of students in Geometry. This test is organized into five blocks and each block has five questions which are arranged sequentially shown on Table 1. Questions 1-5 measure student's understanding at level 0 , questions 6-10 measure student's understanding at level 1 , questions 11-15 measure student's understanding at level 2, questions 16-20 measure student's understanding at level 3 and questions 21-25 measure student's understanding at level 4.

Based on this system, the identification of a student's level of understanding attained by weighted sum is shown in Table 3. If the student does not follow in any of the criteria of determining his/her level of understanding, the cases would be labeled "unfit" of the theory model.

Piaget's Test of Logical Operations (PTLO)is a researcher-made instrument that is used to determine the cognitive development levels of the students in mathematics using Piaget's logical operations namely; classification, seriation, transitivity, proportionality and correlation reasoning. These operations involve reasoning pattern and progress of the learners in dealing with a situation that needs careful analysis and prompt action. Table 4 shows the five (5) Piaget's test of logical operations and their corresponding descriptions based on the abilities of the students.

PTLO is composed of 25 questions which are partitioned into five blocks of increasing level of abilities and each block comprises 5 questions. First block of questions measures student's ability for classification while second block of questions tests the student's ability for seriation. The third, fourth and fifth blocks of questions evaluate student's ability for transitivity, proportionality and correlation, respectively. If the students possess the abilities of classification, seriation and transitivity, they are classified as concrete operational thinkers. If they acquire the abilities of proportionality and correlation, they are said to be formal operational thinkers. The concrete and formal operational thinkers are both categorized into stages namely; early concrete, mid concrete and late concrete and early formal and late formal, respectively.

Table 5 shows the process of the identification of the levels of cognitive development of the college students based on Piaget's Test of Logical Operations as used in this study. 
Table 1. Identification of case/criterion

\begin{tabular}{ll}
\hline Acronym & Description of case/criterion \\
\hline C3 & Classic case, 3 of 5 correct answers \\
C4 & Classic case, 4 of 5 correct answers \\
M3 & Modified case, 3 of 5 correct answers \\
M4 & Modified case, 4 of 5 correct answers \\
\hline
\end{tabular}

Table 2. Weighted points awarded by case/criterion met

\begin{tabular}{llll}
\hline For meeting the criterion on: Block & Level & & Points awarded \\
\hline Questions 1-5 & 1 & 0 & 1 \\
Questions 6-10 & 2 & 1 & 2 \\
Questions 11-15 & 3 & 3 & 4 \\
Questions 16-20 & 4 & 4 & 8 \\
Questions 21-25 & 5 & 16 & 16 \\
\hline
\end{tabular}

Table 3. Identification of level attained by weighted sum

\begin{tabular}{ll}
\hline Weighted sum of & Level \\
\hline 0 or 16 & 0 \\
1 or 17 & 1 \\
3 or 19 & 2 \\
7 or 23 & 3 \\
15 or 31 & 4 \\
\hline
\end{tabular}

Table 4. Piaget's test of logical operations

\begin{tabular}{ll}
\hline Operations & Descriptions \\
\hline Classification & $\begin{array}{l}\text { Ability to name and identify sets of objects according to appearance, size, or other characteristics, including the } \\
\text { idea that one set of objects can include another }\end{array}$ \\
$\begin{array}{l}\text { Seriation } \\
\text { Transitivity }\end{array}$ & $\begin{array}{l}\text { Ability to sort objects in an order according to size, shape or any other characteristics } \\
\text { Proportionality } \\
\text { Correlation }\end{array}$ \\
$\begin{array}{l}\text { Ability to determine the relative magnitude of the increase and decrease of ratios } \\
\text { Ability to recognize a comparison between the number of confirming and disconfirming cases of ahypothesized } \\
\text { relationship to the total number of cases }\end{array}$ \\
\hline
\end{tabular}

Table 5. Scoring continuum for Piaget's test of logical operations

\begin{tabular}{llll}
\hline Score & Stage & Logical operation & Level \\
\hline $1-5$ & Early concrete & Classification & 1 \\
$6-10$ & Mid-concrete & Seriation & 2 \\
$11-15$ & Late concrete & Transitivity & 3 \\
$16-20$ & Early formal & Proportionality & 4 \\
$21-25$ & Late formal & Correlation & 5 \\
\hline
\end{tabular}

Using the scores as basis for the identification of the levels the college students belong, they are classified according to different stages.

Geometry Achievement Testis a 35-item researchermade questionnaire that tests the intellectual capacity of the students in Geometry. The reliability test results of this instrument showed a Cronbach alpha value of 0.927 which suggested that the said instrument is very highly reliable. The description clearly manifested that all items on the instruments were just taken from previous research questionnaires.

\section{Statistical Techniques}

- These are the statistical tools used to analyze and interpret the data

- Frequency and Percentage were used to describe the demographic profile of the students
- To determine the cognitive development levels and attitudes of the students using Perry's scheme, Piaget's theory and van Hiele's levels of thinking, mean was used

- Analysis of Variance was used to compare the cognitive development levels when grouped according to age, gender and course

- Pearson product moment correlation (r) was used to determine the relationship between cognitive development levels using Piaget's theory and van Hiele's level of thinking and achievement of students in mathematics

- To determine which theory and cognitive levels best predict students achievement in mathematics particularly geometry, stepwise multiple regression analysis was used 


\section{Presentation, Analysis and Interpretation of Data}

In this chapter, the results of the study and the comprehensive discussions of the findings are presented.

\section{Profile of the College Students}

Table 6 shows the profile of the college students in terms of age, gender and year level. In terms of age, the categorization is based on the fact that the youngest age involved in the study is 16 years old while the oldest age is 24 years old.

It is evident that most of the respondents come from the age brackets of 16-17 years old with a frequency of 50 which comprise $47.6 \%$ of the total population. The number is not surprising because most of these students belong to first year and second year levels.

The age brackets of 18-19 years old have frequency of 38 which consist of $36.2 \%$ of the respondents whereas the remaining frequency of $17(16.2 \%)$ belong to the age brackets of 20 years old and up.

For profile of gender, female group has the most number of respondents having frequency of 77 which give $73.3 \%$ of the entire population. Male group, on the other hand, makes up the remaining $26.7 \%$ having frequency of 28.

For year level profile, first year level gives the highest frequency of $45(42.86 \%)$, second year level comes next which has $32(30.48 \%)$, fourth year level follows with $18(17.14 \%)$ while the third year level has the least number of participants which only have 10 which covers barely $9.5 \%$ of the overall participants.

\section{Identification of the Level of Cognitive Development of College Students in Geometry Based on Van Hiele's Levels of Thinking}

In the initial stage of the study, the college students were measured using the four case/criterion scenarios. There were about 105 college math major students who took the test where 45 of them are first year, 32 belong to second year, only 10 come from third year and 18 students are from fourth year level. Table 7 presents the breakdown of students who fit the Van Hiele's model by case or criterion and this could give the researcher an idea as to what case/criterion to be used for careful analysis of the data.

As revealed on the preceding table, 68 (64.76\%) out of 105 are classified under classic case 3 of 5 correct or C3, $32(30.48 \%)$ are identified under classic case 4 of 5 correct or C4, $71(67.62 \%)$ belong to modified case 3 of 5 correct of M3, $34(32.38 \%)$ are classified under M4 or modified case, 4 of 5 correct whereas 20(19.05\%) out of 105 are not fitting to the Van Hiele model thus this will not be the subject of the analysis.

Based on the results of the breakdown of the college students who fit the Van Hiele model, M3 (modified case, 3 of 5 correct answers) was used to identify the Van Hiele's levels of the college students because this case/criterion scenario gives a higher percentage of the respondents to be analyzed.

Table 8 shows the frequency of the college students at each level of cognitive development based on Van Hiele's model per year level. Most of the respondents of the first year and second year levels are classified with Level 2 (analytic thinking). According to the Van Hiele model, the students in this level focus explicitly on properties or attributes of shape. Moreover, the mathematical proofs may be explicitly misunderstood and unappreciated in this particular level.

Out of 105 participants of the study, only one who comes from the fourth year level or barely $0.95 \%$ reaches to the Level 4 (rigorous thinking). At this level, student appreciates the investigation of various systems and able to reason to in the most rigorous manner within the various systems. None from first year to third year students think rigorously.

The findings were supported by the study of Mateya (2008) that majority of her research participants are at the pre-recognition level and Van Hiele levels 1 and 2. It implied further that the students who participated in the study are functioning at a level of geometric thinking not fitting with their mathematics curriculum. Atebe and Schafer (2010) suggested that the learning and teaching of Geometry at senior secondary phase should reach Van Hiele level 4 (formal deduction).

\section{Identification of the Levels of Cognitive Development of College Students in Geometry Based on Piaget's Concrete and Formal Operations}

Table 9 shows the levels of the college students identified based on Piaget's Test of Logical Operations. As revealed, out of 105 college students there are 3 $(2.86 \%)$ classified as early concrete operational thinkers. These students are able to name, identify sets of objects but unable to sort things out.

Twenty-two (22) of them which comprise of about $20.95 \%$ are mid concrete operational thinkers. They are able to sort things out according to their sizes, shape and appearance but unable to identify the relationship that exists between them.

Moreover, there $36(34.29 \%)$ of them are classified as late concrete operational thinkers. These students are able to recognize relationship among various things in a serial order but unable to determine the relative magnitude of the ratios involve in the given problem. The concrete operational thinkers have the ability to classify objects, sort things in an orderly manner and recognize relationship among entities which are classified according to the logical operations of classification, seriation and transitivity. 
Table 6. Profile of the college students

\begin{tabular}{lllr}
\hline Profile & Categories & Frequency $(\mathrm{N}=105)$ & Percentage \\
\hline \multirow{3}{*}{ Age } & $16-17$ & 50 & 47.60 \\
& $18-19$ & 38 & 36.20 \\
\multirow{3}{*}{ Gender } & 20 and up & 17 & 16.20 \\
& Male & 28 & 26.70 \\
& Female & 77 & 73.30 \\
Year Level & First year & 45 & 42.86 \\
& Second year & 32 & 30.48 \\
& Third year & 10 & 9.52 \\
\hline
\end{tabular}

Table 7. Breakdown of college students who fit the Van Hiele's models by

\begin{tabular}{lll}
\hline Case/criterion identification & Frequency & $(\%)$ \\
\hline C3 (Classic case, 3 of 5 correct) & 68 & 64.76 \\
C4 (Classic case, 4 of 5 correct) & 32 & 30.48 \\
M3 (Modified case, 3 of 5 correct) & 71 & 67.62 \\
M4 (Modified case, 4 of 5 correct) & 34 & 32.38 \\
Not fit & 20 & 19.05 \\
\hline
\end{tabular}

Table 8. Frequency of college students who are identified based on Van Hiele's level of thinking

\begin{tabular}{|c|c|c|c|c|c|c|c|}
\hline \multirow[b]{2}{*}{ Year level } & \multicolumn{7}{|c|}{ Frequency } \\
\hline & Not fit & Level 0 & Level 1 & Level 2 & Level 3 & Level 4 & Total \\
\hline First year & 8 & 11 & 21 & 4 & 1 & 0 & 45 \\
\hline Second year & 6 & 2 & 13 & 10 & 1 & 0 & 32 \\
\hline Third year & 2 & 1 & 2 & 2 & 3 & 0 & 10 \\
\hline Fourth year & 4 & 0 & 2 & 4 & 7 & 1 & 18 \\
\hline Overall & 20 & 14 & 38 & 20 & 12 & 1 & 105 \\
\hline
\end{tabular}

Table 9. Identification of the levels of college students based on Piaget's test of logical operations

\begin{tabular}{llllr}
\hline Operational stage & Level & Logical operation & Frequency & $(\%)$ \\
\hline Concrete operational & & & 3 & 2.86 \\
1.1 Early concrete & 1 & Classification & 22 & 20.95 \\
1.2 Mid concrete & 2 & Seriation & 36 & 34.29 \\
1.3 Late concrete & 3 & Transitivity & 39 & 37.14 \\
Formal operational & & & 5 & 4.76 \\
2.1 Early formal & 4 & Proportionality & $\mathrm{N}=105$ \\
2.2 Late formal & 5 & Correlation & 100.00 \\
Total & & & & \\
\hline
\end{tabular}

Under formal operational thinkers, this is categorized into two stages namely; early formal and late formal operations. There are 39 college students who are classified as early operational thinkers. These students are able to determine the relative magnitude of the increase and decrease or ration but unable to recognize comparison between the number of confirming and disconfirming cases of a hypothesized relationship to the total number of cases.

There are only 5 of them who are classified as late formal operational thinkers. These students are capable of deductive and hypothetical reasoning and have the ability to formulate hypothesis and answer problem systematically and logically.

The result is consistent with the study of Leongson and Limjap (2002) that they found results alarming because most of these students are at the age of 17 and up who are expected to perform at the formal operational level, however, the findings revealed that the students were barely identified at the concrete operational level. It is evident that there are about 61 college students or roughly $58.1 \%$ classified as concrete operational thinkers. According to Piaget, concrete operations stages have ages ranging from 7 years old to 11 years old. However, these students who happened to be the respondents of the study have ages ranging from 16 to 24 years old.

It shows that many respondents do not perform task expected on their age brackets. This could be the reason why most of the students are not successful in doing any mathematical tasks and eventually failed in mathematics. 
The result is congruent to the study done by Shayer and Wylan (1978) that less than fifteen (15\%) of sixteen-year-old British middle and secondary school children showed evidence of formal operational thinking and by Ehindero (1976) revealed that only (40\%) showed the attainment of formal operations.

\section{Level of Achievement of College Students in Geometry}

Table 10 displays the level of achievement of college students in Geometry. As revealed on the table, there are only 8 students who got scores ranging from 90-94 which comprise $7.62 \%$ of the entire respondents. Sixteen (16) or barely $15.24 \%$ come from scores ranging from 85-89 whose scores are described as satisfactory. Fair number of students around 37 (35.24\%) who got scores ranging from 80-84.

There are $16(26.66 \%)$ of them obtained percentage scores ranging from 75-79. The scores range is described as needs improvement. It means that the students need enhancement activity that will increase achievement in Geometry.

Furthermore, quite alarming number of 28 which comprise $26.66 \%$ of the entire population and even more startling that they got scores which are described as failed. These students got scores ranging from 74 and below. The overall average is 79 which is qualitatively described as "needs improvement". The result implies that the performance of the college students in Geometry is poor and thus, the teacher should look into ways on how to ferret out distinctive remedy to solve this problem. The reason could be traced as to how Geometry is being taught and the findings revealed that learning and teaching Geometry is mainly focused on Van Hiele levels 1 and 2 with a small amount of Geometry work being done at level 3 .

Significant Difference in the Van Hiele's Levels of Thinking when Grouped according to Age, Gender and Year Level

Table 11 shows the significant difference in the Van Hiele's Levels of Thinking of college students when grouped according to age, gender and year level. It also presents the post hoc test in ANOVA that is designed for situations in which the significant omnibus F-test has already been obtained. This has a factor that consists of three or more means and additional exploration of the differences among means is needed to provide specific information on which means are significantly different from each other. The gender effect can be interpreted directly since there are only two levels of the factors namely; male and female.

As revealed, the F-value of the age profile with respect to the Van Hiele's Levels of Thinking of college students is 9.485 with a probability value of 0.000 . The result leads to the rejection of the null hypothesis. This implies that there is significant difference in the Van Hiele's level of thinking when the respondents are grouped according to age brackets.

The students whose ages range from 20 years old and up have higher mean of 12.55 as compared to 18 -19 years old with a mean of 10.72 and 16-17 years old having an average of 8.71 points.

Regarding the profile of gender with respect to the Van Hiele's levels of thinking, the T-value is 4.300 with a $p$-value of 0.042 . The value indicates that the null hypothesis is rejected. This implies that there is significant difference between male and female in the Van Hiele's levels of thinking. The male group has a mean rating of 11.24 in Van Hiele Geometry test while female group obtains a mean rating of 9.66. Results show that male group performs better in the test than female group. The findings go with the perception of one interviewee who said that male performs better in mathematics as compared to the female because men are innate logical thinkers.

Many research findings in Nigeria have shown that boys perform better than the girls in Geometry generally despite the fact that they are put under the same classroom situation (Etukudo, 2002). This is contrary to the study conducted by Agwagah (1993) who reported that female students perform significantly better than their male counterparts. The study also agreed with the assertions that gender difference may exist but a good method should be capable of neutralizing the difference. However, in the study of Achor et al. (2009) revealed that the results provide empirical evidence that achievement in Geometry depend on the method of instruction adopted and are not influenced by gender .

In the profile of year level with respect to the difference in the Van Hiele's level of thinking of college students, the p-value is 9.650 which value suggests to the rejection of the null hypothesis. The result shows a significant difference in the Van hiele's levels of thinking when the respondents are grouped according to year level. As shown in the former table, the first year college students has a mean rating in the Van Hiele's Geometry test of 8.92 , a mean rating of 9.25 for the second year students and 13.14 and 12.36 mean ratings obtained by the third year and fourth year students, respectively. The mean result indicates that third year students perform better in the test as compared to the other year levels.

Genz (2006) conducted a study to determine high school geometry students' geometric understanding using Van Hiele levels and revealed that the students were not adequately prepared to understand the concepts of Geometry, as they were presented in the high school Geometry course and found the levels of reasoning in Geometry to be hierarchical. 
Table 10. Level of achievement of college students in geometry

Performance in geometry

\begin{tabular}{llll} 
Scores & Frequency & (\%) & Description \\
\hline $90-94$ & 8 & 7.620 & Good \\
$85-89$ & 16 & 15.24 & Satisfactory \\
$80-84$ & 37 & 35.24 & Fair \\
$75-79$ & 16 & 15.24 & Needs \\
Improvement 74 and below & 28 & 26.66 & Failed \\
Average improvement & 79 & & Needs \\
\hline
\end{tabular}

Table 11. Significant difference in the Van Hiele's levels of thinking when grouped according to age, gender and year levels

\begin{tabular}{|c|c|c|c|c|}
\hline \multirow[b]{2}{*}{ Profile } & \multicolumn{4}{|c|}{ Van Hiele's levels of thinking } \\
\hline & $\mathrm{N}$ & Mean & $\mathrm{T} / \mathrm{F}$-value & p-value \\
\hline Age (in years): & & & 9.485 & .000 \\
\hline $16-17$ & 31 & $8.71^{\mathrm{a}}$ & & \\
\hline $18-19$ & 29 & $10.72^{\mathrm{bc}}$ & & \\
\hline 20 and up & 11 & $12.55^{\mathrm{c}}$ & & \\
\hline Gender: & & & 4.300 & .042 \\
\hline Male & 21 & 11.24 & & \\
\hline Female & 50 & 9.66 & & \\
\hline Year level & & & 9.650 & .000 \\
\hline First year & 26 & $8.92^{\mathrm{a}}$ & & \\
\hline Second year & 24 & $9.25^{\mathrm{a}}$ & & \\
\hline Third year & 7 & $13.14^{\mathrm{b}}$ & & \\
\hline Fourth year & 14 & $12.36^{\mathrm{b}}$ & & \\
\hline
\end{tabular}

*Column means with the same letter are not significantly different using Tukey HSD test at 0.05 level

Fuys et al. (1988) pointed out that a student has to go through the levels consecutively, otherwise he or she will not be able to perform geometrical task. They agreed that it was important to follow the order of the Van Hiele theory's levels in Geometry.

According to Van Hiele (1986), the teaching process comes to an end with this final phase indicating that the students have reached a new level of thought and have increased their thought level in the new subject matter. This means that the student summarizes all that he or she learned about the subject, reflects on his or her actions and obtains an overview of the whole network or field that has been explored (Fuys et al., 1988).

As revealed by post hoc analysis, there is a significant difference on the Van Hiele's levels of thinking between age bracket of 16-17 years and $18-19$ years and age bracket of 16-17 years and 20 years and up.

Results also show that there is no significant difference on the Van Hiele's levels of thinking between age brackets of 18-19 years and 20 years and up. This implies that the two age brackets have the same Van Hiele's levels of thinking.

Significant Difference in the Piaget's Theory of Concrete and Formal Operations when Grouped according to Age, Gender and Year Level

Table 12 presents the significant difference in the Piaget's Theory on Concrete and Formal Operations when grouped according to age, gender and year level and the post hoc analysis in ANOVA. The results reveal a significant difference on the age profile with respect to their rating in Piaget's Test of Logical Operations. In fact, those students belonging to ages 20 and up obtain a mean rating of 17.82 than the students at the age brackets of 18-19 years old and 1617 years old which have mean ratings of 15.83 and 12.94 , respectively.

In the profile of gender, the male group has a mean rating of 15.19 while the female group has 14.74 . The tvalue is 0.137 which has a $p$-value of 0.713 . The result fails to reject null hypothesis.

The findings imply that there is no significant difference in the Piaget's Concrete and Formal Operation when grouped according to gender. This implies further that both genders have equal performances in Piaget's Test of Logical Operations. Males, more than females, perceive mathematics as an appropriate activity for males by stereotyping mathematics as a male domain (Fennema, 1977).

In the profile of year level, the fourth year students got the highest mean rating of 18.59 while third year students obtained 18.29. Second year students have mean rating of 15.42 while the first year students who got the lowest mean rating of 11.46 . The F-value resulted to 13.887 which gave a p-value of 0.000 . 
This result tends to reject the null hypothesis. This means that there is significant difference on Piaget's concrete and formal operations when analyzed according year level. This means further that fourth year students perform better in the test as compared to the other year levels. The findings suggest that the result is due to the fact that in this year level, the students become increasingly competent and they use logical operations in abstract way rather than at the concrete way of thinking. This study implies further that the higher the level of cognitive development the student is, the better he performs in Geometry. This conforms with the study conducted by Leongson and Limjap (2002) that as individual goes through the four successive cognitive levels of performance, the expertise of reasoning develops progressively.

Correlation among Cognitive Development Theories and the Achievement of College Students in Geometry

Table 13 presents the correlation among cognitive development theories and the achievement of college students in Geometry. As shown in the table, the correlation value (r) between Van Hiele's Level of Thinking and achievement in Geometry is 0.558 with a p-value of 0.000 . The results suggest that the null hypothesis is rejected. This means that there is significant relationship between Van Hiele's levels of thinking and the Geometry achievement of the college students. This implies that if the Van Hiele's level of thinking of the students is higher, the achievement of the college students in Geometry tends also to be higher.

The table also shows the correlation between Piaget's Theory of Concrete and Formal Operations and the achievement of the college students in Geometry. The correlation value $(r)$ gives a numerical equivalent of 0.702 and the $p$-value is 0.000 . These values tend to reject the null hypothesis. This means that there is significant relationship between Piaget's Theory of Concrete and formal Operations and the achievement of the college students in Geometry. The findings imply that if the students reach the formal operations stage, the higher they can achieve in Geometry test.

Stepwise Multiple Regression Analysis on the Levels of Cognitive Development that Best Predict Students' Achievement in Geometry

Table 14 shows the stepwise multiple regression analysis on the variables which are the levels of cognitive development of Van Hiele and Piaget's theory towards the achievement of the college students in Geometry. As revealed, the beta coefficients of the levels of two cognitive development theories are positive which means that these variables significantly contribute to the variance of the achievement in Geometry.
Under the Van Hiele's levels of thinking, the $\mathrm{R}^{2}$ value of 0.565 indicates that the variation of the achievement can be explained by the two levels of cognitive development in the model namely deduction and rigorous. This means that deduction and rigorous significantly contributed to the achievement in Geometry. This implies further that the student achieve higher in Geometry if they reach level 3 and level 4 in the Van Hiele's levels of thinking.

It explains further that the students should think deductively and rigorously to be successful in Geometry. This also implies that the remaining percentage which is about $50.8 \%$ of the variation of the achievement can be attributed to the other variables. This conforms with the study of Mateya (2008) that most students who performed better in Geometry are most likely those who have been identified from level 3 to level 4 .

The regression formula of Van Hiele's levels of thinking can be given by Geometry Achievement = $7.84+2.96$ (Rigorous) +2.91 (Deductive). The formula reveals that for every unit increase of Van Hiele's rigorous level of thinking, there corresponds to a 2.96 unit increase in the achievement of students in Geometry. Additionally, for every unit increase in Van Hiele's deductive level of thinking, there is an approximately 2.21 unit increase in the achievement in Geometry. These findings are affirmed with the NCTM (2000) principles and standards which consider conceptual and procedural knowledge which are relevant to the study of mathematics particularly in teaching Geometry.

Under the levels of cognitive development of Piaget's theory of concrete and formal operations, there are three levels that appear to be the predictors of students' achievement in Geometry. It has a beta coefficient of 0.61 and statistically significant $(p<$ 0.05 ). The levels of transitivity, proportionality and correlation are statistically significant while the levels of classification and seriation are not significant. This predictors have coefficient multiple determination ( $\mathrm{R}$ -squared) of 0.751 which indicates that $75.1 \%$ of the variance in achievement in Geometry is accounted for or influenced by these levels.

Based on the results of determining the best predictors to students' achievement in Geometry using the levels of cognitive development of Van Hiele and Piaget's theory, the null hypothesis is rejected. This denotes that students identified as deductive and rigorous thinkers excel in the Geometry achievement test while that of the Piaget's theory, the students identified as possessing levels of transitivity, proportionality and correlation are also performing better in Geometry. 
Table 12. Significant difference in the Piaget's theory of concrete and formal operations when grouped according to age, gender and year level

\begin{tabular}{|c|c|c|c|c|}
\hline \multirow[b]{2}{*}{ Profile } & \multicolumn{4}{|c|}{ Piaget's concrete and formal operations } \\
\hline & $\mathrm{N}$ & Mean & T/F-value & p-value \\
\hline Age (in years) & & & 6.319 & 0.003 \\
\hline $16-17$ & 31 & $12.94^{\mathrm{a}}$ & & \\
\hline $18-19$ & 29 & $15.83^{b c}$ & & \\
\hline 20 and up & 11 & $17.82^{c}$ & & \\
\hline Gender & & & 0.137 & 0.713 \\
\hline Male & 21 & 15.19 & & \\
\hline Female & 50 & 14.74 & & \\
\hline Year level & & & 13.887 & 0.000 \\
\hline First year & 26 & $11.46^{\mathrm{a}}$ & & \\
\hline Second year & 24 & $15.42^{b}$ & & \\
\hline Third year & 7 & $18.29^{b}$ & & \\
\hline Fourth year & 14 & $18.59^{b}$ & & \\
\hline
\end{tabular}

*Column means with the same letter are not significantly different using Tukey HSD test at 0.05 level

Table 13. Correlation among cognitive development theories and the achievement of college students in geometry Geometry achievement test

Cognitive development theories

Van Hiele's level of thinking

$\begin{array}{ll}\text { r } & \text { p-value } \\ 0.558^{* *} & 0.000\end{array}$

Piaget's theory of concrete and formal operations

$\begin{array}{ll}0.702 * * & 0.000\end{array}$

Legend: ${ }^{* *}$ Correlation is significant at 0.01 level (two-tailed)

Table 14. Multiple regression analysis on the predictors of students' achievement in geometry

\begin{tabular}{|c|c|c|c|c|c|}
\hline \multirow[b]{2}{*}{ Predictor model } & \multirow{2}{*}{$\begin{array}{l}\text { Unstandardized coefficients } \\
\text { B }\end{array}$} & \multicolumn{4}{|c|}{ Standardized coefficients } \\
\hline & & Std. Error & Beta & t-value & Sig. \\
\hline \multicolumn{6}{|c|}{ Van Hiele's levels of thinking } \\
\hline Constant & & 7.84 & 0.31 & $12.32 * *$ & 0.000 \\
\hline Level 1-Analytic & 0.37 & 0.18 & 0.25 & 2.35 & 0.069 \\
\hline Level 2-Abstract & 1.26 & 0.15 & 0.19 & 3.12 & 0.058 \\
\hline Level 3-Deductive & 2.21 & 0.24 & 0.15 & $5.30 * *$ & 0.032 \\
\hline Level 4-Rigorous & 2.92 & 0.12 & 0.17 & $8.32 * *$ & 0.000 \\
\hline \multicolumn{6}{|c|}{$\begin{array}{l}\text { Piaget's theory on concrete } \\
\text { and formal operations }\end{array}$} \\
\hline Constant & 9.85 & 0.61 & & $9.24 * *$ & 0.000 \\
\hline Level 1-Classification & 0.92 & 0.87 & 0.52 & 5.23 & 0.095 \\
\hline Level 2-Seriation & 1.79 & 0.57 & 0.37 & 13.56 & 0.072 \\
\hline Level 3-Transitivity & 2.31 & 0.48 & 0.52 & $3.73 * *$ & 0.030 \\
\hline Level 4-Proportionality & 2.57 & 0.26 & 0.37 & $8.49 * *$ & 0.002 \\
\hline Level 5-Correlation & 2.94 & 0.21 & 0.20 & $5.94 * *$ & 0.000 \\
\hline
\end{tabular}

Van Hiele's level: Multiple $\mathrm{R}=0.432 \mathrm{R}$-squared $=0.565$ F-ratio $=8.46$ P-value $=0.002$ Piaget's Theory: Multiple $\mathrm{R}=0.652 \quad \mathrm{R}$ squared $=0.751$ F-ratio $=14.34$ P-value $=0.000 * *$ Correlation is significant at 0.05 level (two-tailed)

This conforms to the study of Leongson and Limjap (2002) that individuals with higher level of cognitive performance excel in solving problems that require varied logical process skills while those with lower level of cognitive performance find hard in solving problems. The result implied further that students attained expertise as they are able to raise their cognitive skill achievement at a higher level.

\section{Conclusion and Recommendation}

This chapter presents the summary of relevant findings, its implication to mathematics instruction, conclusion and recommendations.
The study evaluated the cognitive development levels of Bachelor of Science in Education major in mathematics students of Holy Cross of Davao College, Davao City and their achievement in Geometry using Piaget's Test of Logical Operations and Van Hiele's Geometry Test. This was anchored on the two known cognitive development theories namely; Piaget's Theory on Concrete and Formal Operations and Van Hiele's Levels of Thinking.

The researcher employed quantitative approach to research. The statistical tools used to analyze and interpret the data were frequency and percentage distributions for the profile, arithmetic mean for the determination of the cognitive development levels of the students using Piaget's Test of Logical Operations and 
Van Hiele's Geometry Test and Geometry Achievement Test, analysis of variance to compare the significant difference when grouped according to age, gender and year level, Pearson product moment correlation (Pearson-r) to determine the extent of relationship between cognitive development levels and achievement in Geometry and stepwise-multiple regression analysis to predict students' achievement in Geometry.

Based on the findings of the study, the researcher concludes the following:

- There are total of 105 respondents of the study in which 71 of them are considered for further analysis because these students fit the Van Hiele modified case/criterion (M3) 3 of 5 correct answers. Most of them belong to age bracket of 16-17 years old, female and first year students

- Most of the college students are identified as concrete operational thinkers using Piaget's theory of concrete and formal operations who possess the levels of classification, seriation and transitivity

- Using Van Hiele's levels of thinking, most of the students are classified as holistic thinkers. This implies that the students perform poorly in Geometry because they are only able to recognize the physical aspect of phenomenon and they lack logical and hypothetical reasoning

The college students in general have low achievement in Geometry test.

There is a significant difference on the cognitive development levels using Van Hiele's levels of thinking when grouped according to age, gender and year level. This implies that those students whose ages ranging from 20 years old and up are performing better in Geometry as compared to the other age brackets. It also reveals that male students are performing better than female students and exposes finding that third year students outperform other year levels in their achievement in Geometry.

On the cognitive development levels using Piaget's theory on concrete and formal operations, there is a significant difference when grouped according to age and year levels just like Van Hiele's levels of thinking but found a non-significant difference when grouped according to gender. This reveals that both male and female students have the same achievement in Geometry.

There are significant positive relationships among Van Hiele's levels of thinking, Piaget's theory of concrete and formal operations and Geometry achievement test. This implies that the students perform better in Geometry if they reach Van Hiele's levels of deductive and rigorous thinking and Piaget's levels of transitivity, proportionality and correlation.

Van Hiele's levels of deductive and rigorous thinking and Piaget's levels of transitivity, proportionality and correlation are significant predictors in the achievement of students in Geometry. This implies that in order to be successful in learning Geometry and mathematics in general, the student must reach Van Hiele' level 3 - deductive thinking and Piaget's level 3 -transitivity.

\section{Recommendation}

In the light of the aforementioned results and findings, the researcher would like to recommend the following:

The Department of Education (DepEd) should strengthen the Philippine basic education system by sustaining the $\mathrm{K}$ to 12 curriculum to ensure quality education for the Filipino people.

Curriculum developers and policy-makers should revisit mathematics curriculum with specific reference to Van Hiele's levels 4 which is rigorous thinking and align Geometry curricula with the Van Hiele's levels of thinking.

Teachers in Geometry should ensure that students understand and know the properties of different shapes and they are given opportunities to discuss their geometric thoughts and understanding to address language barrier which is English as a medium of instruction.

\section{Acknowledgement}

This very important project could not have been made possible without the support and generous assistance of the people who are instrumental to the success of this study. Thus, the researcher would like to extend his heartfelt gratitude to the Central Mindanao University (CMU) professors Dr. Nenita I. Prado, Dr. Raul C. Orongan, Dr. Rolito G. Eballe and Dr. Denis A. Tan for their brilliant ideas and constructive comments and suggestions that undoubtedly made greater improvement of the paper.

$\mathrm{He}$ is also indebted to Dr. Anthony M. Penaso, Dr. Fe Ann Yebron, Dr. Alnar Detalla and Dr. Danilo I. Mejica, for their continuous encouragement and professorial concern that help this paper to keep on moving.

My special acknowledgement to my parents Luz and Rudy for being an inspirations to make this study successfully done.

Finally, all the glory and honors be with the Almighty Father for making all these things possible.

\section{Ethics}

Prior to the conduct of the study, the researcher sought an approval to ensure protection of the respondents. He upheld the principles of confidentiality and privacy by providing the respondents with full understanding of the purpose of the study and a description of how the data would be gathered from them. On the other hand, the author would like to request future researchers to acknowledge him once the paper is cited as reference materials for their study. 


\section{References}

Achor, E.E., B.I. Imoko and S.E. Uloko, 2009. Effect of ethnomathematics teaching approach on senior secondary students' achievement and retention in Locus. Educ. Res. Rev.

Agwagah, U.N., 1993. Instructions in mathematics reading as a factor in students' achievement and interest in word problem-solving. PhD Thesis, University of Nigeria, Nsukka.

Atebe, H.U. and M. Schafer, 2010. Research evidence on geometric thinking level hierarchies and their relationship with Mathematic performance. J. Sci. Teachers Association Nigeria.

De Villiers, M.D., 1996. The future of secondary school geometry. Learning Math., 1: 1-7.

Ehindero, O.J., 1976. Relationship between Piagetian cognitive development at the formal level and science background among prospective elementary school teachers. Oregon State University.

Etukudo, U.E., 2002. The effect of computer-assisted instruction on gender and performance of junior secondary school students in mathematics. Abacus, J. Math. Association Nigeria.

Fennema, E., 1977. Influences of selected cognitive, affective and educational variables on sex-related differences in mathematics, learning and studying. National Inst. Educ. Papers (DHEW), Washington, DC.

Feza, N. and P. Webb, 2005. Assessment standard, van Hiele levels and grade seven learners' understanding of geometry. Pythagoras, 62: 36-47.

Fuys, D., D. Geddes and R. Tischler, 1988. The van Hiele model of thinking in geometry among adolescents. J. Res. Math. Education.

Genz, R., 2006. Determining high school geometry students' geometric understanding using van Hiele levels: Is there a difference between standards-based curriculum students and nonstandards-based curriculum. PhD Thesis, Brigham Young University.

Higgins-Trenk, A. and A.J.H. Gaite, 1970. Elusiveness of formal operational thought. Proceedings of the 70th Annual Convention of the American Psychological Association, (APA’ 70), pp: 201-200.
Hoffer, A., 1981. Van Hiele Based Research. In: Acquisition of Mathematics Concepts and Processes Lesh R. and M. Landau (Eds.), Academic Press, New York, pp: 205-227.

Kuhn, D., 2012. Cognitive Development. 1st Edn., Columbia University, New York.

Lawson, A. and J. A. Renner, 1974. Quantitative analysis of responses to Piagetian tasks and its implications for curriculum. Sci. Educ., 58: 545-559.

Leongson, J.A. and A.A. Limjap, 2002. Assessing the mathematics achievement of college freshmen using Piaget's logical operations. Manila.

Mateya, M., 2008. Using van Hiele theory to analyse geometrical conceptualization in grade 12 students: A Namibian perspective. $\mathrm{PhD}$ Thesis, Rhodes University.

Mayberry, J., 1983. The van Hiele levels of geometric thought in undergraduate Preservice teachers. J. Res. Math. Educ., 14; 58-69.

NCTM, 2000. Principals and Standards for School Mathematics. 1st Edn., National Council of Teachers of Mathematics, Reston, ISBN-10: 0873534808, pp: 402.

Pegg, J., 1995. Learning and Teaching Geometry. In: Teaching Secondary School Mathematics: Theory into Practice L. Grimison (Ed.), Harcourt Brace, London, pp: 87-103.

Renner, J.W. and G. Stafford, 1972. The Operational Levels of Secondary School Students. In: Research, Teaching and Learning with the Piaget Model, Renner, J.W., D.G. Stafford, A.E. Lawson, J.E. McKinnear and E. Friot et al. (Eds.), University of Oklahoma Press, Norman.

Shayer, M. and H. Wylan, 1978. Group tests of cognitive development ideals and a realization. J. Res. Sci. Teaching.

Teppo, A., 1991.Van Hiele levels of geometric thoughts revisited. Math. Teachers, 84: 210-221.

Van Hiele, P.M., 1986. Structure and Insight: A Theory of Mathematics Education. 1st Edn., Academic Press, Orlando.

Wankat, P.C. and F.S. Oreovics, 1983. Analysis of student mistakes and improvement of problem solving on McCabe-Thiele Binary distillation tests. AIChE Symp. Ser., 79: 33-33.

Wells, K.R., 2004. Developmental psychology: Cognitive development. 